\title{
Hubungan Pemakaian dan Penatalaksanaan Garam Beriodium Skala Rumah Tangga dengan Status Iodium Balita di Kabupaten Blitar dan Kediri
}

\section{Relationship of Usage and Management of Iodized Salt on A Household Scale with Iodine Status on Children Under Five Years of Age in Blitar and Kediri District}

\author{
Elya Sugianti \\ Badan Penelitian dan Pengembangan Provinsi Jawa Timur
}

DOI: https://doi.org/10.32781/cakrawala.v12i2.278

\begin{tabular}{l}
\hline ARTICLE INFO \\
Balita \\
GAKI \\
Garam \\
Status Iodium \\
Iodine Status \\
Iodine Deficiency Disorders \\
Children Under Giver Years \\
of Age \\
Salt \\
\hline
\end{tabular}

Article History:

Received : Oktober 2018

Accepted : December 2018

\begin{abstract}
Abstrak:
Masalah GAKI merupakan masalah kesehatan yang belum terselesaikan. Selama ini pemakaian garam beriodium digunakan sebagai upaya dalam menanggulangi masalah GAKI. Namun, dalam dua tahun terakhir, kegiatan pemantauan garam beriodium skala rumah tangga sudah tidak dilakukan. Tujuan dari penelitian ini adalah untuk menganalisis pemakaian dan penatalaksanaan garam beriodium pada skala rumah tangga terhadap status iodium balita. Penelitian ini merupakan penelitian kuantitatif dengan desain cross sectional. Pengumpulan data dilakukan dengan wawancara responden dan pengujian laboratorium. Jumlah sampel pada penelitian ini sebanyak 95 balita. Analisis data menggunakan uji chi square dan spearman. Hasil penelitian ini adalah pemakaian garam beriodium pada skala rumah tangga mampu menjaga status iodium balita pada kondisi optimal. Namun, masih terdapat defisiensi dan kelebihan iodium pada balita. Meskipun pada panelitian ini pemakaian dan penatalaksanaan garam beriodium pada skala rumah tangga tidak berhubungan dengan kejadian GAKI pada balita $(p>0,05)$, namun, pemakaian dan penatalaksanaan garam beriodium dengan baik penting dalam mengeliminasi GAKI pada masyarakat.
\end{abstract}

\section{Abstract:}

Iodine deficiency disorders are unresolved health problems. During this time the usage of iodized salt on a household scale was used as an effort in tackling iodine deficiency disorders problems. However, in the past two years, monitoring of the usage of iodized salt on a household scale have not been carried out. The purpose of this study was to analyze the relationship of the usage of iodized salt on a household scale with iodine status of children under five years of age. This research is a quantitative research that uses a cross sectional design. Data collection using respondent interviews and laboratory testing. The number of samples in this study were 95 children under five years of age. Data analysis used chi square and spearmans. The results of this study are that the usage of iodized salt on a household scale is able to maintain iodine status of children under fiver years of age on optimal conditions. However, there was still a deficiency and excess iodine in children under fiver years of age. Although in this study the usage and management of iodized salt on a household scale was not related to iodine deficiency disorders incidence in children under five years of age $(p>0.05)$, however, the usage and management of iodized salt on a household scale with good, be important in eliminating iodine deficiency disorders in the community.

Cite this as:

Sugianti, E. (2018). Hubungan Pemakaian dan Penatalaksanaan Garam Beriodium Skala Rumah Tangga dengan Status Iodium Balita di Kabupaten Blitar dan Kediri. Cakrawala, 12(2). 145-156. https://doi.org/10.32781/cakrawala.v12i2.278.

$\begin{array}{ll} & \\ & \\ \text { Corresponding author : } \\ \text { Address } \quad \text { Jl. Gayung Kebonsari No.56, Gayungan, Kota } \\ & \text { SBY, Jawa Timur 60235 } \\ \text { Email } & : \text { sugiantielya@gmail.com } \\ \text { Phone } \quad:\end{array}$




\section{Pendahuluan}

GAKI (Gangguan Akibat Kekurangan Iodium) merupakan salah satu masalah gizi yang belum terselesaikan. Istilah GAKI didefinisikan sebagai sekumpulan gejala akibat kekurangan iodium secara terus menerus dan dalam jangka waktu yang lama. Survei GAKI tahun 2003, Total Goiter Rate (TGR) nasional sebesar 11,1\%. Sementara Riset Kesehatan Dasar (Riskesdas) Tahun 2013 menemukan bahwa sebanyak 14,9\% anak umur 6-12 tahun; 22,1\% wanita usia subur; $24,1 \%$ ibu hamil, dan $23,9 \%$ ibu menyusui memiliki ekskresi iodium urin dalam kategori kurang.

GAKI disebabkan kurangnya asupan iodium tingkat berat terutama pada daerah-daerah pegunungan yang memiliki kandungan iodium dalam tanah dan air yang sangat kurang. GAKI dapat berpengaruh pada penurunan kualitas sumber daya manusia. Hal ini karena dampaknya dimulai dari neonatal sampai dewasa dan bersifat permanen. GAKI dapat menyebabkan keguguran, kecacatan janin, gondok, keterbelakangan mental, kretin, serta penurunan kecerdasan.

Jawa Timur merupakan salah satu provinsi di Indonesia dengan tingkat endemisitas GAKI kategori sedang $(24,8 \%)$. Sementara Blitar dan Kediri pada survei GAKI tahun 2003 masing-masing memiliki tingkat endemisitas GAKI kategori berat (47,47\% dan 36,13\%). Masih tingginya endemisitas GAKI pada kedua kabupaten tersebut menjadikan alasan pemilihan sebagai lokasi penelitian.

Salah satu program penanggulangan GAKI adalah fortifikasi iodium pada garam. Universal Salt Iodization (garam beriodium untuk semua) adalah program jangka panjang untuk mengeliminasi masalah GAKI. Masalah GAKI diperkirakan dapat dieliminasi apabila lebih dari 90\% rumah tangga telah mengonsumsi garam yang mengandung cukup iodium. Riset Kesehatan Dasar
2013 menemukan bahwa hasil tes cepat iodium dalam garam, sebanyak 24,6\% rumah tangga di Jawa Timur mengonsumsi garam dengan kandungan iodium kategori kurang, sedangkan di Kabupaten Blitar dan Kediri masing-masing sebanyak $15,7 \%$ dan $22,6 \%$ rumah tangga yang mengonsumsi garam dengan kandungan iodium kategori kurang. Berbeda dengan itu, Pemantauan Status Gizi (PSG) Tahun 2016 menemukan bahwa presentase rumah tangga yang mengonsumsi garam beryodium di Kabupaten Blitar dan Kediri berturut-turut sebesar $81,6 \%$ dan $93,0 \%$.

Selama dua tahun terakhir, monitoring garam beriodium skala rumah tangga belum dilakukan lagi. Hal inig mengakibatkan tidak adanya update data gambaran dampak pemakaian garam beriodium skala rumah tangga. Dampak GAKI yang cukup serius bagi kualitas sumber daya manusia dan belum adanya updating data pemkaian garam beriodium pada kedua kabupaten menjadikan alasan mengapa masalah ini perlu untuk dikaji. Tujuan dari penelitian ini adalah menganalisis hubungan pemakaian dan penatalaksanaan garam beriodium pada skala rumah tangga dengan status iodium pada balita.

\section{Tinjauan Pustaka}

\section{A. Iodium}

Iodium merupakan zat gizi mikro yang penting dalam sintesis hormon tiroid. Iodium berfungsi dalam stabilitas metabolisme dan fungsi organ tubuh. Hormon tiroid penting peranannya pada pertumbuhan dan perkembangan manusia (Kemenkes, 2016b). Iodium dalam makanan atau minuman masuk dalam tubuh dalam bentuk ion iodat atau iodida. Ion iodat akan dirubah menjadi iodide di dalam lambung. Iodium dari berbagai sumber makanan akan diabsorbsi di saluran pencernaan, kemudian didistribusikan ke dalam cairan ekstraseluler, kelenjar 
liur, mukosa lambung, dan kelenjar susu dalam bentuk iodida organik. Konsentrasi iodida organik dalam cairan eksktraseluler berkorelasi terhadap asupan iodium, namun biasanya rendah konsentrasinya akibat cepatnya ambilan tiroidal dan bersihan ginjal.

\section{B. Kebutuhan Iodium}

WHO merekomendasikan asupan iodium sebesar $90 \mathrm{mcg}$ per hari untuk anak umur 0-5 tahun, $120 \mathrm{mcg}$ per hari untuk anak umur 6-12 tahun, $150 \mathrm{mcg}$ per hari untuk anak diatas 12 tahun dan dewasa serta 250 mcg per hari untuk ibu hamil dan menyusui. Sementara rekomendasi medis asupan iodium minimal setiap hari adalah: $90 \mathrm{mcg}$ per hari untuk anak umur 1-8 tahun, 120 mcg per hari untuk anak 9-13 tahun, 150 mcg per hari untuk dewasa, 220 mcg per hari untuk ibu hamil dan $290 \mathrm{mcg}$ untuk ibu menyusui (Kemenkes, 2016b)

\section{Garam Beriodium}

Garam beriodium merupakan strategi program dalam mencukupi kebutuhan iodium pada populasi dengan cara fortifikasi/ penambahan iodium pada garam. Garam beriodium diproses dengan cara menambahkan potassium iodate (KlO3) atau potassium iodide (KI) ke dalam garam pada saat garam diproduksi. Penambahan KIO3 lebih direkomendasikan dibandingkan dengan potassium iodide (KI) karena dinilai lebih stabil. Indikator keberhasilan upaya penyediaan garam beriodium untuk masyarakat adalah kadar iodium dalam garam. Sejak tahun 1994, WHO dan Unicef merekomendasikan program garam beriodium untuk semua (Universal Salt Iodization) dengan target mencapai lebih dari 90\% (Kemenkes, 2016b).

\section{Pemakaian garam beriodium}

Pemakaian garam beriodium yang memenuhi target lebih dari 90\% merupakan upaya dalam mengeliminasi GAKI pada masyarakat (Kemenkes, 2016b). Namun, beberapa penelitian menemukan bahwa kandungan iodium pada garam rumah tangga tidak memenuhi Standar Nasional Indonesia, yaitu kandungan KIO3 dalam garam berkisar antara 10,7020,33 ppm (Agustin dkk, 2015). Apika dkk (2017) menemukan bahwa sebagian besar responden penelitian menggunakan garam beriodium kurang dari $<30 \mathrm{ppm}$. Penelitian yang dilakukan oleh Ashar dkk (2016) terhadap anak sekolah dasar di Kabupaten Wonosobo dan Temanggung juga menemukan bahwa sebanyak 59,2\% rumah tangga mengonsumsi garam dengan kandungan iodium $<30 \mathrm{ppm}$.

Sementara Amalia dkk (2015) menemukan bahwa hampir semua ibu rumah tangga menggunakan garam yang berlabelkan garam beriodium, namun hanya $11 \%$ rumah tangga dengan kandungan garam beriodium kategori cukup (30 ppm). Demikian halnya dengan penelitian yang dilakukan oleh Kartono dkk (2014) yang menemukan bahwa hampir semua responden menggunakan garam dalam bentuk bata dengan hasil titrasi rata-rata sampel garam mengandung $20.4 \pm 10.5$ ppm pada anak dan dewasa di Kecamatan Getasan, Kabupaten Semarang.

Irawati dkk (2011) menemukan bahwa tingkat konsumsi garam beriodium ibu hamil di Gunung Kidul sebagian besar termasuk dalam kategori rendah $(<$ $175 \mu \mathrm{g} / \mathrm{l})$ dan sebagian besar garam yang dikonsumsi berjenis briket/ balok. Muftiana dan Munawaroh (2016) menemukan bahwa garam yang dikonsumsi sehari-hari adalah garam kasar pada rumah tangga yang memiliki anggota keluarga dengan retardasi mental di Kabupaten Ponorogo. Demikian halnya penelitian yang dilakukan oleh Mulyantoro dkk (2014) yang menemukan bahwa hampir semua responden membeli garam berbentuk bata. 
Beberapa penelitian terdahulu telah menemukan adanya hubungan antara pemakaian garam beriodium dengan kejadian GAKI. Penelitian yang dilakukan oleh Hariyanti dan Indrawati (2013) pada anak sekolah dasar di Kecamatan Kendal, Kabupaten Ngawi menemukan bahwa pemakaian garam beriodium berhubungan kuat dengan kejadian GAKI. Demikian halnya penelitian yang dilakukan oleh Kusuma dan Budiono (2016), juga menemukan adanya hubungan antara pemakaian garam beriodium dengan kejadian GAKI pada anak usia sekolah dasar di Kabupaten Temanggung.

\section{E. Penatalaksanaan garam beriodium}

Penatalaksanaan garam beriodium merupakan praktek yang dilakukan oleh rumah tangga dalam penyimpanan dan peletakan garam beryodium, praktek pembubuhan garam, dan penggunaan penutup saat memasak. Agustin dkk (2015) menemukan bahwa sebanyak $39,1 \%$ ibu rumah tangga menyimpan garam dengan penyimpanan yang kurang benar, yaitu garam beryodium disimpan dalam wadah yang tidak tertutup, lebih dari separuh ibu rumah tangga membubuhkan garam pada saat proses memasak, dan sebagian besar ibu rumah tangga tidak menggunakan penutup saat merebus makanan. Namun, Agustin dkk (2015) menemukan bahwa sebagian besar responden meletakkan wadah garam dengan baik, yaitu tidak terkena cahaya, tidak dekat api, tidak berarir dan tidak lembab. Meskipun penatalaksanaan garam beryodium masih belum tepat, namun, penatalaksanaan garam rumah tangga yang tidak baik tidak berhubungan dengan kejadian GAKI di Kecamatan Koto Tangah (Agustin dkk, 2015).

Sementara itu, Mulyantoro dkk (2014) menemukan bahwa sebagian besar responden menempatkan garam dalam wadah kering, tertutup dan jauh dari panas. Penelitian yang dilakukan oleh Muftiana dan Munawaroh (2016) menemukan bahwa sebagian besar responden menyimpan garam dalam wadah plastik pada rumah tangga yang memiliki anggota keluarga dengan retardasi mental di Kabupaten Ponorogo. Mulyantoro dkk (2014) menemukan bahwa sebanyak 51,1\% responden menggunakan garam beryodium pada akhir memasak, sisanya menggunakan garam pada waktu menghaluskan bumbu dan menambahkannya pada saat awal memasak.

Menurut Wijawati dan Asiarini (2017), garam beryodium yang disimpan dalam wadah tertutup memiliki kadar ppm lebih tinggi dibandingkan dengan garam beryodium dalam wadah terbuka. Sementara rata-rata kadar iodium garam beryodium yang tidak terpapar panas memiliki kadar ppm yang lebih tinggi dibandingkan dengan garam beryodium yang terpapar panas.

\section{F. Gangguan Akibat Kekurangan Iodium (GAKI)}

GAKI adalah sekumpulan gejala atau kelainan yang ditimbulkan karena tubuh menderita kekurangan iodium secara terus-menerus dalam waktu yang lama. GAKI berdampak pada pertumbuhan dan perkembangan manusia. GAKI dibagi dalam beberapa stadium, kretin endemik yang ditandai terutama oleh gangguan mental, gangguan pendengaran, gangguan pada anak dan dewasa, kadar hormon rendah sehingga menyebabkan angka lahir dan kematian janin meningkat (Sudargo $\mathrm{dkk}, 2015$ )

Ada 2 metode yang umum dan relatif murah dilakukan untuk menentukan status GAKI, yaitu pemeriksaan kelenjar gondok dengan metode palpasi dan penentuan ekskresi iodium urin (Sudargo dkk, 2015). Kadar ekskresi iodium urin selalu berbanding lurus dengan asupan iodium selama 24 jam. Ekskresi iodium urin merupakan gambaran terbaik asupan 
iodium individu dalam sehari. Namun, penentuan kadar ekskresi iodium urin hanya dapat digunakan untuk mengukur status GAKI pada populasi, yaitu dengan mengukur median kadar ekskresi iodium urinnya. Median ekskresi iodium urin dapat digunakan untuk keperluan pemetaan, pemantauan dan penilaian keberhasilan program penanggulangan GAKI pada masyarakat (Kemenkes, 2016b).

\section{Metode Penelitian}

\section{A. Lokasi dan Waktu Penelitian}

Penelitian ini dilaksanakan di Kabupaten Blitar dan Kediri. Lokasi penelitian dipilih secara purposif dengan pertimbangan bahwa kedua kabupaten tersebut memiliki riwayat endemik GAKI tingkat berat, yaitu sebesar 47,47\% di Kabupaten Blitar dan 36,13\% di Kabupaten Kediri. Dari kedua kabupaten tersebut selanjutnya masingmasing dipilih dua puskesmas secara purposive (Puskesmas Slumbung dan Garum di Kabupaten Blitar, Puskesmas Ngadi dan Tiron, di Kabupaten Kediri). Pemilihan keempat puskesmas tersebut berdasarkan data daerah riwayat endemic GAKI dari dinas kesehatan kabupaten. Adapun jangka waktu penelitian adalah delapan bulan (Maret-Oktober 2018).

\section{B. Pendekatan Penelitian}

Pendekatan penelitian ini adalah penelitian kuantitatif. Penelitian ini termasuk penelitian observasional dengan desain cross sectional. Desain penelitian ini menekankan pengambilan data dalam satu waktu tertentu.

\section{Metode Pengumpulan Data}

Sebanyak 95 balita berumur 24-59 bulan terlibat dalam penelitian ini. Teknik pengampilan sampel dilakukan secara random sampling. Jenis variabel yang diambil dalam penelitian ini meliputi meliputi karakteristik responden (umur, jenis kelamin, berat dan panjang lahir, umur ibu, pendidikan orang tua, pekerjaan orang tua, besar keluarga, dan penghasilan keluarga), pemakaian garam beriodium skala rumah tangga (bentuk garam konsumsi dan kualitas garam konsumsi), dan penatalaksanaan garam beriodium skala rumah tangga (wadah simpan garam, letak garam, keterpaparan cahaya matahari, waktu bubuh garam dan penggunaan penutup saat memasak), serta kadar ekskresi iodium urin. Data karakteristik responden dan penatalaksanaan garam beriodium diperoleh melalui wawancara dengan kuesioner terstruktur. Data jenis garam yang dikonsumsi diperoleh melalui pengamatan. Data tentang kualitas garam beriodium responden diperoleh melalui pengukuran semikuantitatif dengan iodine test. Sementara data status iodium diperoleh melalui pengujian laboratorium sampel urin balita. Adapun status iodium didasarkan pada kriteria sebagai berikut: status iodium rendah apabila nilai kadar ekskresi iodium urin $<100 \mu \mathrm{g} / \mathrm{L}$ ), status iodium cukup apabila nilai kadar ekskresi iodium urin 100-199 $\mu \mathrm{g} / \mathrm{L}$, dan status iodium berlebih apabila kadar ekskresi iodium urin $>200 \mu \mathrm{g} / \mathrm{L}$. Pengumpulan data dilakukan oleh lulusan D3 gizi yang sudah terlatih.

\section{Analisis Data}

Analisis data dalam penelitian ini terbagi menjadi dua, yaitu analisis univariat dan bivariat. Analisis univariat menggunakan tabulasi frekuensi. Sementara analisis bivariat dengan uji chi square dan spearman yang digunakan untuk melihat hubungan antara pemakaian dan penatalaksanaan garam beriodium dengan status iodium balita.

\section{Hasil dan Pembahasan \\ A. Karekteristik Balita}

Proporsi terbesar balita berumur pada kisaran 24-36 bulan dan berjenis kelamin laki-laki. Sebagian besar balita memiliki berat dan panjang lahir normal. Balita 
memiliki ibu yang berumur dewasa muda, dan berasal dari keluarga kecil dengan kondisi sosial ekonomi rendah. Kondisi sosial ekonomi keluarga balita dapat mempengaruhi akses pemilihan pangan dan daya beli terhadap pangan. Seseorang dengan kondisi sosial ekonomi yang tinggi akan dapat leluasa dalam mengakses pangan sehingga ketersediaan pangan dalam rumah tangga lebih terjamin, khususnya pangan alami sumber iodium yang tinggi, demikian sebaliknya. Kondisi sosial ekonomi sebagian besar keluarga balita pada penelitian ini dalam kategori rendah. Kondisi ekonomi responden menyebabkan terbatasnya responden dalam mengakses pangan hewani yang memiliki kandungan iodium yang tinggi. Oleh karena itu, garam beriodium merupakan sumber utama dalam penyediaan asupan iodium pada rumah tangga.

\section{B. Gambaran Pemakaian Garam Beriodium Skala Rumah Tangga}

Garamberiodiumyang digunakanpada skala rumah tangga pada penelitian ini berbentuk halus dan berkategori cukup iodium, namun masih terdapat kesenjangan pada dua kabupaten. Capaian garam beriodium pada lokasi penelitian di Kabupaten Blitar sudah mencapai target 90\%, yaitu sebesar 93,2\%. Sementara di Kabupaten Kediri, capaian garam beriodium di lokasi penelitian baru mencapai 78,4\% rumah tangga. Capaian garam beriodium pada penelitian ini lebih rendah dibandingkan hasil PSG tahun 2017, khususnya di Kabupaten Kediri. Data PSG 2017 menunjukkan bahwa cakupan rumah tangga yang menggunakan garam beriodium sudah mencapai lebih dari 90\%, yaitu 93,9\% di Kabupaten Blitar dan 95,2\% di Kabupaten Kediri (Kemenkes, 2017. Perbedaan capaian ini diduga karena adanya perbedaan sampel dan perbedaan metode pengumpulan data di lapangan.

Beberapa penelitian terdahulu menemukan bahwa sebagian besar masyarakat menggunakan garam beriodium berkualitas rendah (Agustin dkk, 2015; Ashar dkk, 2016; Apika dkk, 2017). Amalia dkk (2015) menemukan bahwa sebagian besar responden sudah menggunakan kemasan garam berlabelkan garam beriodium, namun hanya $11 \%$ responden yang menggunakan garam beriodium kualitas baik. Beberapa penelitian terdahulu juga menemukan bahwa sebagian besar responden menggunakan garam berbentuk curai (Muftiana\& Munawaroh, 2016) dan bata (Irawati dkk, 2011; Kartono dkk, 2014; Mulyantoro dkk, 2014).

Masih belum tercapainya target pemakaian garam beriodium skala rumah tangga pada penelitian ini diduga karena responden masih menggunakan garam berkualitas rendah, seperti penggunaan garam berbentuk kristal di Kabupaten Blitar dan balok/ bata di Kabupaten Kediri. Penggunaan garam beriodium berkualitas rendah oleh masyarakat tidak lepas dari kemudahan akses garam beriodium berkualitas rendah atau tidak mengandung iodium di pasaran. Banyaknya garam berkualitas rendah dan tidak mengandung iodium di pasaran berkontribusi dalam mendorong masyarakat untuk lebih memilih garam beriodium dengan kualitas rendah dan atau tidak mengandung iodium karena harganya yang lebih murah. Kesadaran masyarakat yang belum paham akan dampak GAKI akibat penggunaan garam beriodium kualitas rendah atau non iodium juga berkontribusi pada rendahnya pemakaian garam beriodium skala rumah tangga.

\section{Gambaran Penatalaksanaan Garam Beriodium Skala Rumah Tangga}

Penatalaksanaan garam beriodium sudah baik dalam peletakan garam, keterpaparan terhadap cahaya matahari dan penggunaan penutup pada waktu memasak. Namun, penatalaksanaan garam beriodium belum tepat dalam penyimpanan garam pada wadah simpan dan waktu bubuh garam. Ketersediaan 
Tabel 1. Karakteristik balita

\begin{tabular}{|c|c|c|c|c|}
\hline & \multirow[t]{2}{*}{ Karakteristik Balita } & \multicolumn{3}{|c|}{ Jumlah(\%) } \\
\hline & & $\begin{array}{c}\text { Kab. Blitar } \\
\mathrm{n}=44\end{array}$ & $\begin{array}{c}\text { Kab. Kediri } \\
\quad \mathrm{n}=51\end{array}$ & $\begin{array}{l}\text { Total } \\
\mathrm{n}=95\end{array}$ \\
\hline \multirow[t]{3}{*}{ Umur } & $24-36$ bulan & $20(45,5)$ & $30(58,8)$ & $50(52,6)$ \\
\hline & $37-48$ bulan & $15(34,1)$ & $16(31,4)$ & $31(32,6)$ \\
\hline & $49-60$ bulan & $9(20,5)$ & $5(9,8)$ & $14(14,7)$ \\
\hline \multirow[t]{2}{*}{ Jenis Kelamin } & Laki-laki & $24(54,5)$ & $28(54,9)$ & $52(54,7)$ \\
\hline & Perempuan & $20(45,5)$ & $23(45,1)$ & $43(45,3)$ \\
\hline \multirow[t]{4}{*}{ Berat Lahir } & $<2500$ gram & $1(2,3)$ & $3(5,9)$ & $4(4,2)$ \\
\hline & 2500-3000 gram & $17(38,6)$ & $28(54,9)$ & $45(47,4)$ \\
\hline & $>3000-3500$ gram & $19(43,2)$ & $17(33,3)$ & $36(37,9)$ \\
\hline & $>3500$ gram & $7(15,9)$ & $3(5,9)$ & $10(10,5)$ \\
\hline \multirow{2}{*}{$\begin{array}{l}\text { Panjang Badan } \\
\text { Lahir }\end{array}$} & $<48 \mathrm{~cm}$ & $8(18,2)$ & $6(11,8)$ & $14(14,7)$ \\
\hline & $\geq 48 \mathrm{~cm}$ & $36(81,8)$ & $45(88,2)$ & $81(85,3)$ \\
\hline \multirow[t]{3}{*}{ Umur Ibu } & $<25$ tahun & $5(11,4)$ & $10(19,6)$ & $15(15,8)$ \\
\hline & 25-35 tahun & $22(50,0)$ & $30(58,8)$ & $52(54,7)$ \\
\hline & $>35$ tahun & $17(38,6)$ & $11(21,6)$ & $28(29,5)$ \\
\hline \multirow[t]{4}{*}{ Pendidikan ibu } & Tidak sekolah/SD & $8(18,2)$ & $7(13,7)$ & $15(15,8)$ \\
\hline & SMP & $22(50,0)$ & $22(43,1)$ & $44(46,3)$ \\
\hline & SMA & $14(31,8)$ & $21(41,2)$ & $35(36,8)$ \\
\hline & $\mathrm{D} 3 / \mathrm{S} 1$ & $0(0,0)$ & $1(2,0)$ & $1(1,1)$ \\
\hline \multirow[t]{4}{*}{ Pekerjaan ibu } & Tidak bekerja/IRT & $34(77,3)$ & $40(78,4)$ & $74(77,9)$ \\
\hline & Petani/Buruh & $4(9,1)$ & $3(5,9)$ & $7(7,4)$ \\
\hline & Pedagang/Penjahit/Wiraswasta & $4(9,1)$ & $4(7,8)$ & $8(8,4)$ \\
\hline & PNS/ Karyawan Swasta & $2(4,5)$ & $4(7,8)$ & $6(6,3)$ \\
\hline \multirow{4}{*}{$\begin{array}{l}\text { Pendidikan } \\
\text { ayah }\end{array}$} & Tidak sekolah/SD & $9(20,5)$ & $14(27,5)$ & $23(24,2)$ \\
\hline & SMP & $18(40,9)$ & $21(41,2)$ & $39(41,1)$ \\
\hline & SMA & $15(34,1)$ & $14(27,5)$ & $29(30,5)$ \\
\hline & $\mathrm{D} 3 / \mathrm{S} 1$ & $2(4,5)$ & $2(3,9)$ & $4(4,2)$ \\
\hline \multirow[t]{4}{*}{ Pekerjaan ayah } & Tidak bekerja & $1(2,3)$ & $1(2,0)$ & $2(2,1)$ \\
\hline & Petani/Buruh & $20(45,5)$ & $26(51,0)$ & $44(46,3)$ \\
\hline & Pedagang/Penjahit/Wiraswasta & $20(45,5)$ & $15(29,4)$ & $35(36,8)$ \\
\hline & PNS/ Karyawan Swasta & $3(6,8)$ & $9(17,6)$ & $12(12,6)$ \\
\hline \multirow{2}{*}{$\begin{array}{l}\text { Besar Kelu- } \\
\text { arga }\end{array}$} & Kecil ( $\leq 4$ orang) & $30(68.2)$ & $30(58,8)$ & $60(63.1)$ \\
\hline & Besar ( $>4$ orang) & $14(31,8)$ & $21(41,1)$ & $35(36.9)$ \\
\hline \multirow[t]{4}{*}{ Penghasilan } & $<$ Rp.1,5 juta & $28(63,6)$ & $36(70,6)$ & $64(67,4)$ \\
\hline & Rp. 1,5 juta-Rp. 2,5 juta & $12(27,3)$ & $6(11,8)$ & $18(18,9)$ \\
\hline & Rp. 2,5 juta-Rp. 3,5 juta & $3(6,8)$ & $8(15,7)$ & $11(11,6)$ \\
\hline & $>$ Rp. 3,5 juta & $1(2,3)$ & $1(2,0)$ & $2(2,1)$ \\
\hline
\end{tabular}

Sumber: Data Primer Diolah, 2018

garam beriodium yang sudah baik apabila tidak diimbangi dengan penatalaksanaan kualitas garam beriodium yang tepat, dapat menurunkan kadar iodium pada garam beriodium. Penurunan kadar iodium pada garam berkontribusi terhadap penurunan asupan iodium dari garam 
Tabel 2. Pemakaian Garam Beriodium Skala Rumah Tangga

\begin{tabular}{lllll}
\hline \multicolumn{2}{c}{ Pemakaian garam beriodium } & \multicolumn{3}{c}{ Jumlah (\%) } \\
\cline { 3 - 5 } & $\begin{array}{l}\text { Blitar } \\
\mathrm{n}=44\end{array}$ & $\begin{array}{l}\text { Kediri } \\
\mathrm{n}=51\end{array}$ & $\begin{array}{l}\text { Total } \\
\mathrm{n}=95\end{array}$ \\
\hline Bentuk Garam & $\begin{array}{l}\text { Krosok/ Kristal/ } \\
\text { curah }\end{array}$ & $22(50,0)$ & $0(0,0)$ & $22(23,2)$ \\
& $\begin{array}{l}\text { Briket/ balok/ bata } \\
\text { Kualitas garam }\end{array}$ & $0(0,0)$ & $19(37,3)$ & $19(20,0)$ \\
beriodium & Halus & $22(50,0)$ & $32(62,7)$ & $54(56,8)$ \\
& Cukup & $41(93,2)$ & $40(78,4)$ & $81(85,3)$ \\
& Rendah & $2(4,5)$ & $10(19,6)$ & $12(12,6)$ \\
\hline
\end{tabular}

Sumber: Data Primer Diolah, 2018

beriodium, mengingat bahwa garam beriodium merupakan sumber utama asupan iodium. Kondisi ini dapat mengakibatkan risiko terjadinya GAKI pada masyarakat.

\section{Gambaran Status Iodium pada Balita}

Status iodium pada balita berada pada kisaran optimal. Namun, masih terdapat balita yang memiliki defisiensi dan kelebihan iodium. Kekurangan iodium pada balita diduga karena masih terdapatnya garam beriodium yang tidak standar di pasaran, penatalaksanaan garam beriodium yang belum baik, keterbatasan akses pangan tinggi iodium akibat sosial ekonomi yang rendah, dan tingginya konsumsi pangan goitrogenik/ paparan cemaran/ pestisida. Sementara status iodium berlebih pada balita diduga karena tingginya konsumsi makanan yang mengandung iodium seperti yang terdapat pada susu dan olahannya, produk makanan kemasan/ kalengan/ berpengawet dan penggunaan suplemen dan obat.

Pemakaian garam beriodium merupakan sumber utama dalam penyediaan kecukupan asupan iodium balita pada penelitian ini. Untuk itu, garam beriodium yang tidak sesuai standar harus ditarik dari peredaran. Pendampingan kader terlatih dan atau tenaga kesehatan sangat diperlukan dalam memberikan pemahaman kepada responden terkait dengan GAKI dan dampaknya, manajeman garam beriodium yang baik, perbaikan pola konsumsi pangan tinggi iodium dan pangan penghambat penyerapan iodium serta kendali terhadap konsumsi pangan dengan iodium berlebih pada susu dan makanan berpengawet.

\section{E. Hubungan Pemakaian Garam Beriodium Skala Rumah Tangga dengan Status Iodium pada Balita}

Pemakaian garam beriodium skala rumah tangga tidak berhubungan dengan status iodium pada balita. Hal ini menunjukkan bahwa pemakaian garam beriodium bukan merupakan penyebab masih terdapatnya defisiensi iodium pada balita. Hasil penelitian ini bertentangan dengan beberapa penelitian terdahulu (Sinha et al, 2011; Nurcahyani dkk, 2011; Mulyantoro dkk, 2013) yang menemukan adanya hubungan pemakaian garam beriodium dengan status iodium. Terdapat faktor lain yang menjadi penyebab defisiensi iodium pada balita. Salah satunya diduga adalah karena masih belum baiknya penatalaksaaan garam beriodium tingkat rumah tangga pada penelitian ini. Wadah simpan garam dan waktu bubuh garam responden pada penelitian ini masih belum tepat. Tingginya konsumsi pangan goitrogenik/ paparan cemaran logam berat dan pestisida juga dapat berkontribusi terhadap kejadian GAKI pada balita. Linder (2006) menyatakan bahwa pangan goitrogen dapat menyebabkan penyakit 
Tabel 3. Penatalaksanaan Garam Beryodium Skala Rumah Tangga

\begin{tabular}{|c|c|c|c|c|}
\hline \multicolumn{2}{|c|}{ Pemakaian garam beryodium } & \multicolumn{3}{|c|}{ Jumlah (\%) } \\
\hline & & $\begin{array}{l}\text { Blitar } \\
\mathrm{n}=44\end{array}$ & $\begin{array}{l}\text { Kediri } \\
\mathrm{n}=51\end{array}$ & $\begin{array}{l}\text { Total } \\
\mathrm{n}=95\end{array}$ \\
\hline \multirow{3}{*}{$\begin{array}{l}\text { W a d a } h \\
\text { simpan garam }\end{array}$} & Kantong plastik keadaan terbuka & $2(4,5)$ & $2(3,9)$ & $4(4,2)$ \\
\hline & Toples plastik bening tertutup & $37(84,1)$ & $44(86,3)$ & $81(85,3)$ \\
\hline & $\begin{array}{l}\text { Wadah tertutup dan tidak tembus } \\
\text { pandang }\end{array}$ & $5(11,4)$ & $5(9,8)$ & $10(10,5)$ \\
\hline \multirow[t]{3}{*}{ Letak garam } & Dekat kompor/ api & $7(15,9)$ & $9(17,6)$ & $16(16,8)$ \\
\hline & Rak/ lemari khusus & $25(56,8)$ & $29(56,9)$ & $54(56,8)$ \\
\hline & Meja makan & $12(27,3)$ & $13(25,5)$ & $25(26,3)$ \\
\hline \multirow{2}{*}{$\begin{array}{l}\text { Keterpaparan } \\
\text { cahaya } \\
\text { matahari }\end{array}$} & Ya & $6(13,6)$ & $5(9,8)$ & $11(11,6)$ \\
\hline & Tidak & $38(86,4)$ & $46(90,2)$ & $84(88,4)$ \\
\hline \multirow[t]{3}{*}{$\begin{array}{l}\text { Waktu bubuh } \\
\text { garam }\end{array}$} & $\begin{array}{l}\text { Saat awal memasak/ } \\
\text { menghaluskan bumbu }\end{array}$ & $31(70,5)$ & $28(54,9)$ & $59(62,1)$ \\
\hline & Saat proses memasak & $10(22,7)$ & $19(37,3)$ & $29(30,5)$ \\
\hline & $\begin{array}{l}\text { Saat masakan sudah matang dan } \\
\text { sudah diangkat dari kompor }\end{array}$ & $3(6,8)$ & $4(7,8)$ & $7(7,4)$ \\
\hline \multirow{2}{*}{$\begin{array}{l}\text { Penggunaan } \\
\text { penutup saat } \\
\text { memasak }\end{array}$} & Ya & $32(72,7)$ & $37(72,5)$ & $69(72,6)$ \\
\hline & Tidak & $12(27,3)$ & $14(27,5)$ & $26(27,4)$ \\
\hline
\end{tabular}

Sumber: Data Primer Diolah, 2018

Tabel 4. Kadar Ekskresi Iodium Urin

\begin{tabular}{llll}
\hline \multicolumn{1}{c}{$\begin{array}{c}\text { Kadar Ekskresi Iodium Urin } \\
\text { (EIU) }\end{array}$} & \multicolumn{3}{c}{ Jumlah(\%) } \\
\cline { 2 - 4 } & Kab. Blitar & Kab. Kediri & Total \\
\hline Kategori & $10(22,7)$ & $9(17.6)$ & $19(20,0)$ \\
Defisit $(<100 \mu \mathrm{g} / \mathrm{L})$ & $13(29,5)$ & $18(35.3)$ & $31(32,6)$ \\
Cukup $(100-199 \mu \mathrm{g} / \mathrm{L})$ & $12(27,3)$ & $14(27,5)$ & $26(27,4)$ \\
Lebih dari cukup $(200-299 \mu \mathrm{g} / \mathrm{L})$ & $9(20,5)$ & $10(19,6)$ & $19(20,0)$ \\
Kelebihan $(>300 \mu \mathrm{g} / \mathrm{L})$ & & & 196 \\
Deskripsi Statistik & 196,50 & 188,0 & \\
Median $(\mu \mathrm{g} / \mathrm{L})$ & &
\end{tabular}

Sumber: Data Primer Diolah, 2018

gondok karena terhambatnya sintesis dan sekresi hormon tiroid. Kondisi ini diperparah dengan keterbatasan responden dalam mengakses pangan gizi tinggi dan tinggi iodium. Untuk itu, jaminan ketersediaan garam beriodium kualitas baik merupakan suatu keharusan karena sumber iodium utama responden berasal dari garam beriodium.

\section{F. Hubungan Penatalaksanaan Garam Beriodium Skala Rumah Tangga dengan Status Iodium pada Balita}

Penatalaksanaan garam beriodium skala rumah tangga tidak berhubungan dengan status iodium balita pada penelitian ini. Hasil penelitian ini sejalan dengan penelitian yang dilakukan oleh Agustin dkk (2015) yang tidak menemukan adanya hubungan penatalaksanaan garam beriodium dengan kejadian GAKI di 
Tabel 5. Hubungan Pemakaian Garam Beriodium dengan Kadar Ekskresi Iodium Urin pada Balita

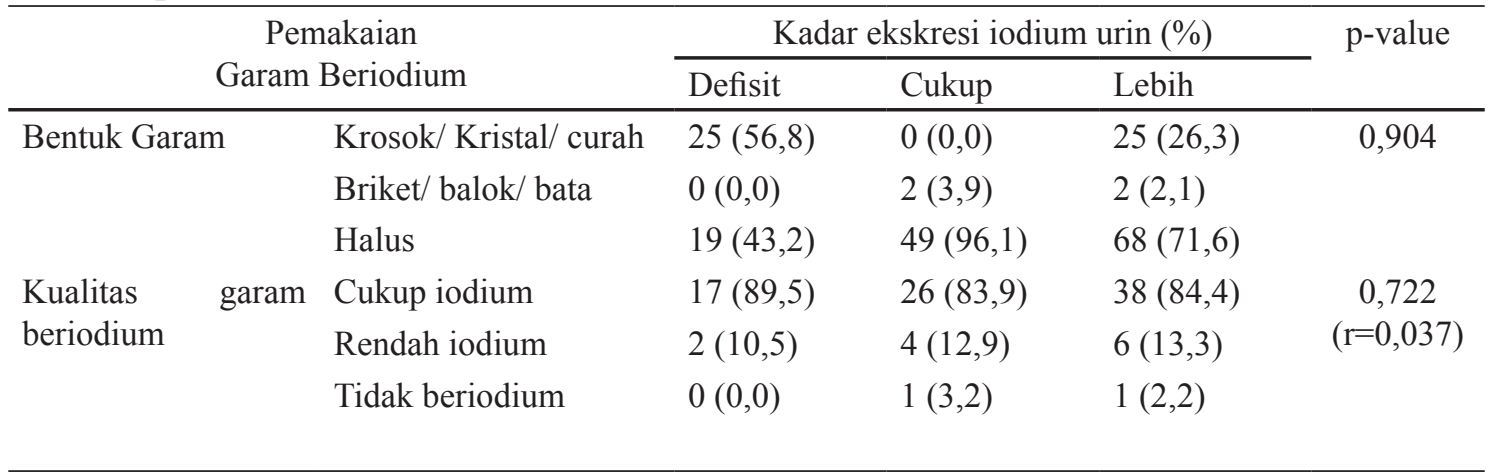

Sumber: Data Primer Diolah, 2018

Tabel 6. Hubungan Penatalaksanaan Garam Beriodium dengan Status Iodium pada Balita

\begin{tabular}{llllll}
\hline \multicolumn{2}{c}{ Penatalaksanaan Garam Beriodium } & \multicolumn{3}{c}{ Kadar ekskresi iodium urin balita (\%) } & \multirow{2}{*}{ p-value } \\
\cline { 3 - 5 } & & Defisit & Cukup & Lebih & \\
\hline \multirow{2}{*}{ Wadah simpan garam } & Tepat & $3(15,8)$ & $3(9,7)$ & $4(8,9)$ & 0,640 \\
& Tidak tepat & $16(84,2)$ & $28(90,3)$ & $41(91,1)$ & \\
Peletakan garam & Tepat & $16(84,2)$ & $26(83,9)$ & $37(82,2)$ & 0,969 \\
\multirow{2}{*}{ STerkena cahaya } & Tidak tepat & $3(15,8)$ & $5(16,1)$ & $8(17,8)$ & \\
& Tepat & $3(15,8)$ & $1(3,2)$ & $7(15,6)$ & 0,184 \\
\multirow{2}{*}{ Waktu bubuh garam } & Tidak tepat & $16(84,2)$ & $30(96,8)$ & $38(84,4)$ & \\
\multirow{2}{*}{ Penggunaan tutup waktu } & Tepat & $1(5,3)$ & $4(12,9)$ & $2(4,4)$ & 0 \\
masak & Tidak tepat & $18(94,7)$ & $27(87,1)$ & $43(95,6)$ & \\
& Tepat & $15(78,9)$ & $21(67,7)$ & $33(73,3)$ & 0,399 \\
\hline
\end{tabular}

Sumber: Data Primer Diolah, 2018

Kecamatan Koto Tangah. Hal ini diduga bahwa defisiensi iodium disebabkan oleh adanya banyak faktor. Penatalaksanaan garam beriodium tidak baik, tidak otomatis membuat defisiensi iodium pada balita (Agustin dkk, 2015). Pembuatan dan pengemasan garam beriodium yang baik sehingga iodium tidak mudah menguap oleh panas dan penyimpanan yang tidak baik diduga menyebabkan tidak adanya hubungan antara penatalaksanaan garam beriodium dengan kejadian GAKI pada penelitian ini.

\section{Simpulan}

Pemakaian garam beriodium pada skala rumah tangga dalam kategori cukup, akan tetapi penatalaksanaan garam beriodium masih belum tepat. Status iodium pada balita dan ibu hamil berada pada kondisi optimal, akan tetapi masih terdapat balita yang mengalami defisiensi dan kelebihan iodium. Pemakaian garam beriodium mampu menjaga status iodium pada balita pada kondisi optimal, meskipun belum terbukti adany hubungan antara pemakaian garam beriodium dan status iodium pada penelitian ini $(p>0,05)$. Pemakaian garam beriodium skala rumah tangga perlu terus digalakkan dalam penanggulangan masalah GAKI pada balita. Perlunya dilakukan pemetaan GAKI, pemantauan kualitas garam beriodium secara rutin level produsen, distributor, dan konsumen. Pendampingan PMBA (Pemberian Makan Bayi dan Anak) secara rutin pada ibu balita 
oleh kader terlatih dan tenaga kesehatan juga diperlukan dalam perbaikan pola konsumsi yang baik.

\section{Ucapan Terima Kasih}

Puji syukur kehadirat Allah atas limpahan rahmat dan hidayah-Nya sehingga penyusunan karya tulis ilmiah ini terselesaikan. Pada kesempatan ini, penulis juga mengucapkan terima kasih dan penghargaaan sebesar-besarnya kepada Kepada Badan Penelitian dan Pengembangan Provinsi Jawa Timur, Kepada Bidang Kemasyarakatan dan Pemerintahan, Badan Penelitian dan Pengembangan Provinsi Jawa Timur, Kepala Dinas Kesehatan Kabupaten Blitar, Kepala Dinas Kabupaten Kediri, Kepala Puskesmas lokasi penelitian beserta staf, ibu balita yang menjadi responden penelitian, serta pihak-pihak yang telah memberikan bantuan dan dukungan sehingga kegiatan penelitian dapat terselesaikan.

\section{Daftar Pustaka}

Agustin, Helfi, Budiman Hary, Faiza Yaumi. (2015). Faktor yang Berhubungan dengan Kejadian Gangguan Akibat Kekurangan Iodium di Kecamatan Kota Tangah, Padang. Jurnal Kesehatan Komunitas 2, 262-269

Amalia, Leily, Permatasari Inke Indah, Khomsan Ali, Riyadi Hadi, Herawati Tin, Nurdiani Reisi. (2015). Pengetahuan, Sikap, dan Praktek Gizi Ibu terkait Iodium dan Pemilihan Jenis Garam Rumah Tangga di Wilayah Pegunungan Cianjur. Jurnal Gizi Pangan 10, 133-140

Apika, Heppy Diah. Dardjito Endo, Purnamasari, Dyah Umiyarni. (2017). Hubungan Kadar Iodium Garam Konsumsi dan Tingkat Konsumsi Iodium dengan Kadar
Ekskresi Iodium Urin (EIU) Wanita Usia Subur. Jurnal Gipas $1,61-70$

Ashar, Hadi, Mulyantoro Donny Kristato, Nurcahyani Yusi Dwi, Khaerunnisa Marizka. (2016). Anemia pada Anak Sekolah Dasar di Daerah Endemik GAKI. Media Gizi Mikro Indonesia 7, 91-98

Hariyanti, Wahyu dan Indrawati, Veni. (2013). Faktor-faktor yang Mempengaruhi Kejadian GAKI pada Anak Usia Sekolah Dasar di Kecamatan Kendal, Kabupaten Ngawi. Journal Boga 2, 150-158

Irawati, Tri Endang, Hadi Hamam, Widodo Untung. (2011). Tingkat Konsumsi Garam Beryodium dan Kaitannya dengan Gangguan Akibat Kekurangan Iodium Ibu Hamil. Jurnal Gizi Klinik Indonesia 8, 1-6

Kartono, Djoko, Samsudin Mohamad, Supadmi Sri. (2014). Perkiraan Asupan Iodium dan Natrium Menggunakan Urin 24 Jam pada Anak dan Dewasa. Media Gizi Mikro Indonesia 5, 71-84

Kementerian Kesehatan. (2013). Riskesdas dalam Angka Provinsi Jawa Timur. Jakarta. Badan Penelitian dan Pengembangan Kesehatan, Kementerian Kesehatan

Kementerian Kesehatan. (2016a). Buku Saku Pemantauan Status Gizi Provinsi Jawa Timur Tahun 2016. Jakarta. Kementerian Kesehatan

Kementerian Kesehatan. (2016b). Surveilans untuk Mengatasi Masalah Gangguan Akibat Kekurangan Iodium. Cetakan 1. Yogyakarta. Pustaka Pelajar 
Kementerian Kesehatan. (2017). Buku Saku Pemantauan Status Gizi Tahun 2017. Jakarta. Kementerian Kesehatan

Kusuma, Septa Tiara, dan Budiono, Irwan. (2016). Faktor Konsumsi yang Berhubungan dengan Kejadian Gangguan Akibat Kekurangan Iodium pada Anak Sekolah Dasar. Unnes Journal of Public Health 2, 149-155

Linder, Maria. (2006). Biokimia Nutrisi dan Metabolisme. Jakarta. Universitas Indonesia Press (UI Press)

Muftiana, Elmie dan Munawaroh, Siti. (2016). Kadar Iodium Garam Rumah Tangga di Desa Krebet, Kabupaten Ponorogo. Jurnal Keperawatan 7, 22-26

Mulyantoro, Donny K, Hakimi Mohammad, Basuki Endro. (2013). Hubungan Kadar Iodium dalam Garam Beryodium di Rumah Tangga dengan Kecukupan Iodium Berdasarkan Nilai Ekskresi Iodium Urin (EIU) pada Wanita Usia Subur. Media Gizi Mikro Indonesia 5, 41-52

Mulyantoro, Donny K, Triastuti Anjar, Setyani Asih. (2014). Hubungan Tingkat Pengetahuan Ibu tentang GAKI, Sikap dan Praktek dengan Kualitas Garam Beriodium di Rumah Tangga. Media Gizi Mikro Indonesia 5, 125-138

Nurcahyani, Y Dwi, Kartono Djoko, Samsudin M. (2011). Korelasi antara Asupan Sumber Iodium pada Wanita Usia Subur. Media Gizi Mikro Indonesia 3, 23-32
Sinha, AK, Tripathi S, Gandhi NK, Sigh AJ. (2011). Iodine Deficiency Disorder Control Programme Impact in Pregnant Women and Status of Universal Salt Iodization. Iranian Journal of Public Health 40, 19-26

Wijawati, Any dan Asiarini, Widi Dwi. (2017). Pengaruh Wadah, Kondisi, dan Cara Penyimpanan terhadap Perubahan Kadar Iodium dalam Garam. Jurnal Ilmu Kesehatan 9, 7-14 